\title{
Preparation and Microwave Absorption Properties of Spherical Cobalt Particles
}

\author{
Sun Wanshuo, Li Hong, Liu Ying, Zhao Xiuchen, Cheng Jingwei, Wen Shulai
}

Beijing Institute of Technology, Beijing 100081, China

\begin{abstract}
Spherical cobalt particles with special morphology were prepared on a large scale through a simple and low-cost liquid reduction method. The morphology, crystal structure, static magnetic properties and electromagnetic behavior of the cobalt particles were measured by SEM, XRD, VSM and vector network analyzer, respectively. The results show that saturation magnetization of the Co particles is $123\left(\mathrm{~A} \cdot \mathrm{m}^{2}\right) / \mathrm{kg}$, less than that of hcp-Co single crystals, and the coercivity is $176 \times 79.6 \mathrm{~A} \cdot \mathrm{m}^{-1}$, larger than that of bulk cobalt crystals. Furthermore, dual-nonlinear dielectric resonances appear at 9.8 and $15 \mathrm{GHz}$. The real part of permeability decreases with the frequency increasing, presenting an excellent frequency dispersion property. Meanwhile, the imaginary part of permeability reveals a wide resonance peak over the microwave frequency range. According to the transmit-line theory, the reflection loss (RL) was predicted through the permittivity and permeability for a given frequency and absorber thickness. A maximum reflection loss of $-13.2 \mathrm{~dB}$ is achieved at $12.4 \mathrm{GHz}$ with a thickness of $5.5 \mathrm{~mm}$, and the effective absorption bandwidth $-10 \mathrm{~dB}$ ) is $1.6 \mathrm{GHz}$, indicating the as-prepared cobalt particles have potential applications as a candidate for microwave absorption.
\end{abstract}

Key words: spherical cobalt particles; liquid reduction method; static magnetic properties; electromagnetic behavior; microwave absorption

In recent years, electromagnetic (EM) interference problems are becoming more and more serious with the development of the electronic technology ${ }^{[1-6]}$. Thus more and more attention has been focused on the materials with superior microwave absorption. To obtain the superior microwave absorption, there are two critical problems to overcome. One is the strong attenuation as the EM-wave goes through the interior of the materials, and the other is the impedance matching between the materials and the air space, which could avoid the high reflectivity when the EM-wave is incident on the surface of the materials. Although various new materials have been investigated for microwave absorption, such as $\mathrm{ZnO}$ nano materials ${ }^{[2,7]}$, carbon-coated $\mathrm{Cu}$ nanocapsules ${ }^{[8]}$, and epoxy polyaniline composites ${ }^{[9]}$, the conventional magnetic metallic materials have irreplaceable advantages. For example, the materials have high saturation magnetization, contributing to high permeability according to Snoek's limit ${ }^{[10]}$. Therefore, high attenuation could be achieved easily due to high magnetic loss. Meanwhile, the materials possess high Curie temperature, so they are suitable for application at high temperature. Nevertheless, the impedance matching is still a challenge to the researchers, ascribed to the high conductivity of the magnetic metallic materials. In general, the way to solve the problem is to synthesize the magnetic metallic particles with sizes less than the skin depth.

We selected the metal cobalt as the research object because of its unique physical and chemical properties, such as catalytic properties ${ }^{[11,12]}$ and structure-dependent magnetic and electronic properties ${ }^{[13]}$. At the same time, various morphologies of cobalt microstructures, including dendritic nanocrystals ${ }^{[14]}$, flower-like spheres ${ }^{[15]}$, sisal-like cobalt superstructures ${ }^{[16]}$ cobalt nanowires ${ }^{[17,18]}$, etc, have been fabricated by many approaches. To our best knowledge, the electromagnetic behaviors and microwave absorption have relation to the morphology of the magnetic particles. Unfortunately, the studies on the effect of the morphology of the cobalt particles on the electromagnetic

Received date: December 16, 2015

Corresponding author: Li Hong, Experimentalist, Beijing Institute of Technology, Beijing 100081, P. R. China, E-mail: 840808@bit.edu.cn

Copyright ( 2016, Northwest Institute for Nonferrous Metal Research. Published by Elsevier BV. All rights reserved. 
behavior and microwave absorption are few. Thus, studies on the cobalt particles for microwave absorption are valuable academically and practically.

Herein, we reported a simple and low-cost liquid reduction method for the cobalt particles synthesis on a large scale, in which $\mathrm{CoSO}_{4} \cdot 7 \mathrm{H}_{2} \mathrm{O}$ acted as cobalt source, $\mathrm{C}_{4} \mathrm{H}_{4} \mathrm{KNaO}_{6} \cdot 4 \mathrm{H}_{2} \mathrm{O}$ as a complexing agent, $\mathrm{N}_{2} \mathrm{H}_{4} \cdot 4 \mathrm{H}_{2} \mathrm{O}$ as a reducing agent, $\mathrm{NaOH}$ as a $\mathrm{pH}$-modifier, and $\mathrm{CTAB}$ as a morphology control agent. The EM parameters of the as-prepared cobalt particles were investigated in the microwave range of $1 \sim 18 \mathrm{GHz}$. According to transmit-line theory, the reflection loss (RL) was predicted through the permittivity and permeability for a given frequency and absorber thickness. The result reveals that the as-prepared cobalt particles have potential applications as candidate for microwave absorption.

\section{Experiment}

All chemicals used in the present work were of analytical grade and used as received without further purification.

Spherical cobalt particles were fabricated by a liquid reduction method. First, $2.81 \mathrm{~g} \mathrm{CoSO}_{4} \cdot 7 \mathrm{H}_{2} \mathrm{O}$ and $16.9 \mathrm{~g}$ $\mathrm{C}_{4} \mathrm{O}_{6} \mathrm{H}_{4} \mathrm{KNa} \cdot 4 \mathrm{H}_{2} \mathrm{O}$ were dissolved in $100 \mathrm{~mL}$ de-ionized water under mechanical stirring for $30 \mathrm{~min}$ at $40{ }^{\circ} \mathrm{C}$, followed by $14 \mathrm{~g} \mathrm{NaOH}$ and $4 \mathrm{~g} \mathrm{C} \mathrm{C}_{16} \mathrm{H}_{33}\left(\mathrm{CH}_{3}\right)_{3} \mathrm{NBr}$ $\left(\mathrm{C}_{16} \mathrm{TAB}\right)$. In the second step, the solution was placed in a three-necked, round-bottom flask container. Then the reaction temperature, the power and the ultrasonic frequency were fixed at $90{ }^{\circ} \mathrm{C}, 1400 \mathrm{~W}$ and $40 \mathrm{kHz}$, respectively. After that, $1 \mathrm{~mL} \mathrm{~N}_{2} \mathrm{H}_{4} \cdot \mathrm{H}_{2} \mathrm{O}$ (80 wt $\%$ ) was quickly added to the above solution. After 15 min reaction, dark grey precipitates appeared. The precipitates were separated from the solution by placing a magnet under the container, and then washed several times with de-ionized water and absolute ethanol to remove all the residual salt. Finally, the products were obtained by drying wet precipitation in a vacuum system at $40{ }^{\circ} \mathrm{C}$ for $24 \mathrm{~h}$.

The morphology of the sample was observed by scanning electron microscope (SEM) (QUANTA600). The phase was examined by X-ray diffraction (XRD) at $50 \mathrm{kV}$ and $30 \mathrm{~mA}$ using Mo $\mathrm{K} \alpha$ radiation $(\lambda=0.07093 \mathrm{~nm})$ on a Bruker D8 $\mathrm{X}$-ray diffractometer. The static magnetic property of the sample was measured using a Lake Shore 7304 vibrating sample magnetometer (VSM).

The EM parameters of the composites containing cobalt particles and paraffin were measured on a vector network analyzer (VNA) in transmission/reflection mode. The spherical cobalt particles were uniformly dispersed in paraffin wax of $50 \mathrm{wt} \%$. Then the composites were pressed into an O-ring VNA specimen (outer diameter $7 \mathrm{~mm}$, inner diameter $3 \mathrm{~mm}$ and thickness $2 \mathrm{~mm}$ ). The electromagnetic parameters were measured on an HP8575E network analyzer. The reflection loss of the as-prepared products was predicted according to the transmit-line theory.

\section{Results and Discussion}

Fig. 1 shows the morphology of the quasi spherical cobalt particles and Fig.1b is the magnified image taken from a selected section in Fig.1a. The size of quasi spherical cobalt particles is mostly in microscale. It is clearly seen that a microsphere is composed of nanoflakes. As shown in Fig.2 EDS spectrum demonstrates the presence of cobalt without other impurities, indicating that the as-prepared products are pure cobalt particles.

Fig. 3 is the X-ray diffraction (XRD) pattern of the cobalt particles at room temperature. It demonstrates that the crystal structure of the cobalt particles is a mixture of fcc (face-centered cubic) and hcp (hexagonal closed packed) structure. It can be well indexed with the reflection of fcc and hcp structure. As shown in Fig. 3, the peaks located at $2 \theta=19.957^{\circ}, 23.086^{\circ}, 32.878^{\circ}, 38.759^{\circ}$ and $40.556^{\circ}$,

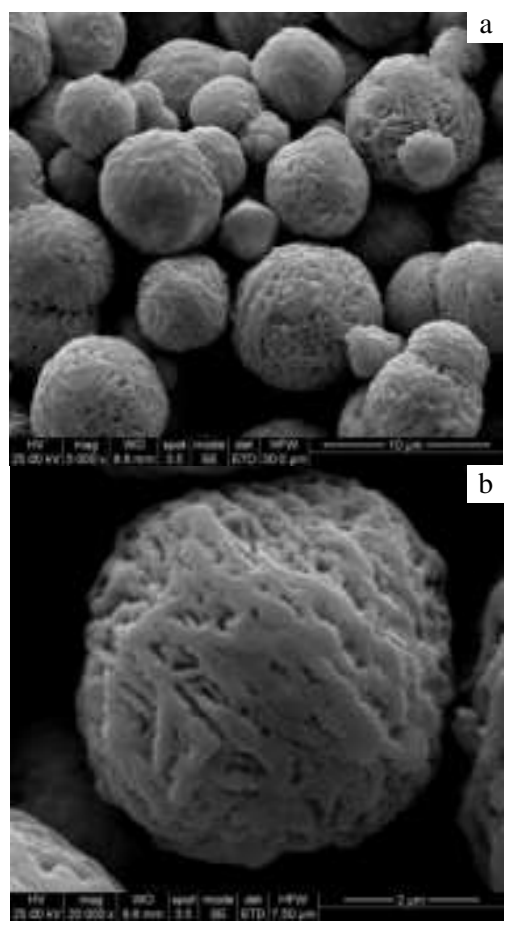

Fig.1 Morphology (a) of the cobalt particles and its magnification (b)

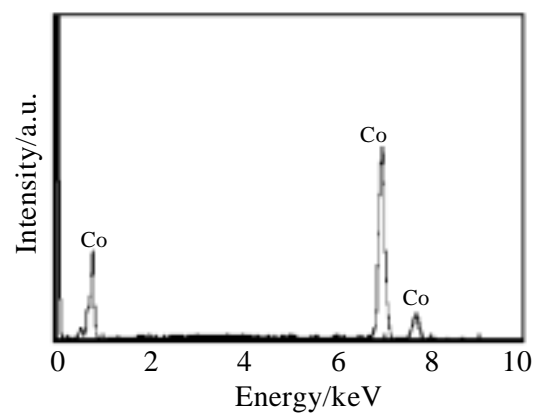

Fig.2 EDS spectrum of the cobalt particles 


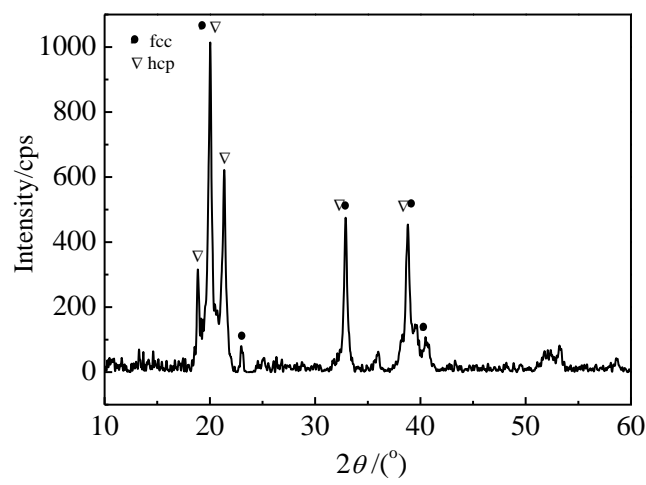

Fig.3 XRD pattern of the cobalt particles

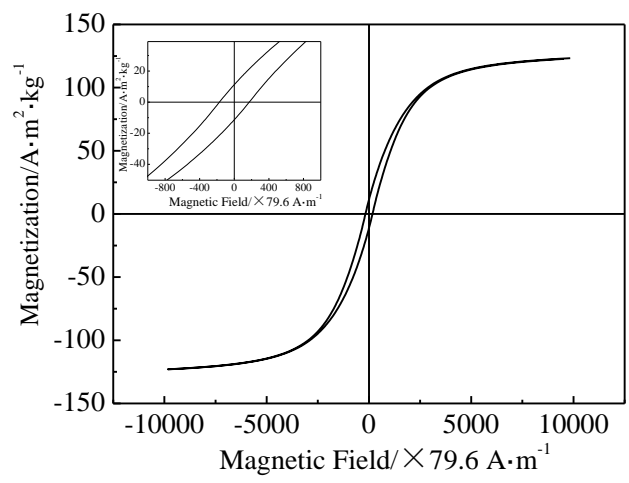

Fig.4 Hysteresis loops of the cobalt particles

higher coercivity is the magnetocrystalline anisotropy of the cobalt particles. The XRD data indicates that the crystal structure is the mixture of the fcc and hcp structure. The hcp-structure possesses larger magnetocrystalline anisotropy. In summary, the increasing of the coercivity might be due to the small size of cobalt particles, the summary effect of surface anisotropy and magnetocrystalline anisotropy.

The permittivity $\left(\varepsilon_{\mathrm{r}}\right)$ and permeability $\left(\mu_{\mathrm{r}}\right)$ of composite specimens containing cobalt particles as fillers were measured in the microwave range of $1 \sim 18 \mathrm{GHz}$, and the results are shown in Fig.5.

As shown in Fig.5a, it can be seen that the real part permittivity $\varepsilon^{\prime}$ of the cobalt particles exhibits less variation $\left(\varepsilon^{\prime}=9.84 \sim 10.1\right)$. For the imaginary part $\varepsilon^{\prime \prime}$, dual-nonlinear dielectric resonances are observed at 9.8 and $15 \mathrm{GHz}$. For the composites with conductive particles dispersed in paraffin matrix, the interfacial electric polarization should be considered. These quasi spherical cobalt particles consist of nanoflakes in the surface of particles. Such special morphology can generate special orientation and interface polarization ${ }^{[22,23]}$. Fig.5b shows the complex permeability of the composites with $50 \mathrm{wt} \%$ cobalt particles in the frequency range of 1 18 GHz. The real part of permeability decreases from 1.38 at $1 \mathrm{GHz}$ to 0.96 at $18 \mathrm{GHz}$ with the frequency increasing, and thus the specimen presents excellent frequency dispersion property. Meanwhile, a wide resonance peak for the imaginary part is revealed over the microwave frequency range.

In general, there are two mechanisms of microwave attenuation in the interior of materials: dielectric loss and magnetic loss. As shown in Fig.6, the dielectric loss $\tan \delta_{\varepsilon}$ of the cobalt particles composite exhibits less variation in the microwave range of $1 \sim 8 \mathrm{GHz}$ and three peaks in the $8 \sim 18$ $\mathrm{GHz}$, while the magnetic loss $\tan \delta_{\mu}$ increases and presents two peaks as high as 0.24 in the $1 \sim 18 \mathrm{GHz}$ range. The magnetic loss $\tan \delta_{\mu}$ of the cobalt particles is larger than the dielectric loss $\tan \delta_{\varepsilon}$. Thus the main contribution of attenuation should be ascribed to magnetic loss. 

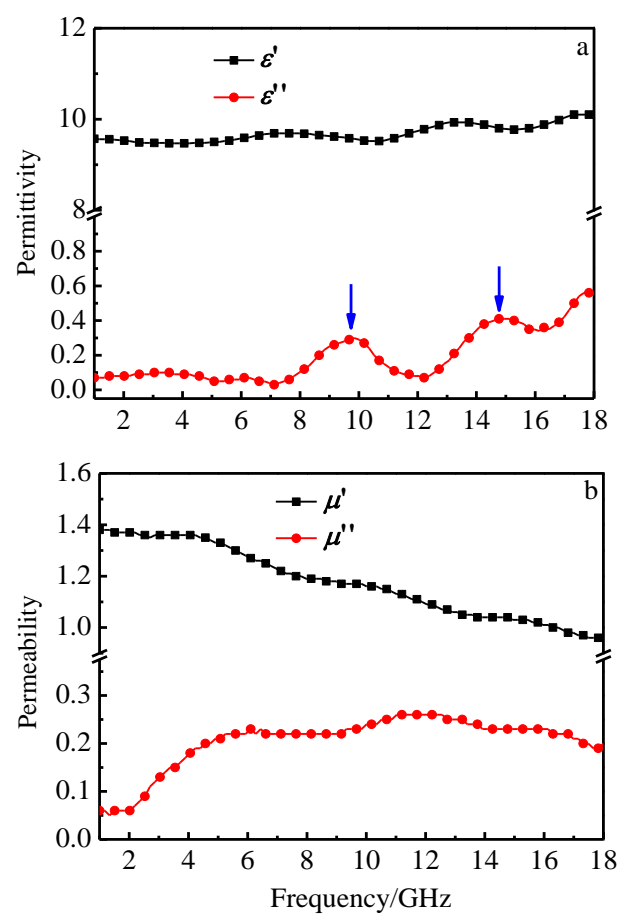

Fig.5 Complex permittivity (a) and permeability (b) of composite specimens with $50 \mathrm{wt} \%$ of cobalt particles

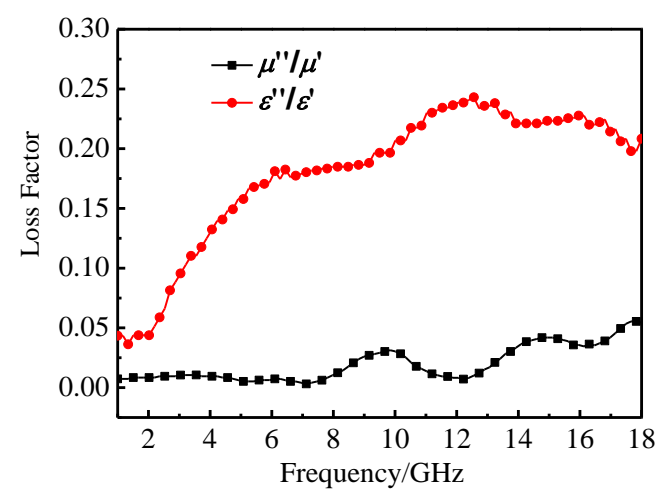

Fig.6 Dielectric loss $\left(\tan \delta_{\varepsilon}=\varepsilon^{\prime \prime} / \varepsilon^{\prime}\right)$ and magnetic loss $\left(\tan \delta_{\mu}=\mu^{\prime \prime} / \mu^{\prime}\right)$ for the composite specimens with 50 wt $\%$ cobalt particles

The reflection loss (RL) was predicted from the permittivity and permeability for a given frequency and absorber thickness, according to the following equations ${ }^{[24]}$ :

$$
\begin{aligned}
& Z_{\text {in }}=Z_{0}(\mu / \varepsilon)^{1 / 2} \tanh \left[j(2 \pi f d / c)(\mu \varepsilon)^{1 / 2}\right] \\
& \mathrm{RL}=20 \lg \left|\left(Z_{\text {in }}-Z_{0}\right) /\left(Z_{\text {in }}+Z_{0}\right)\right|
\end{aligned}
$$

where, $f$ is the frequency of the EM wave, $d$ is the thickness of the absorber, $c$ is the velocity of the light, $Z_{0}$ is the

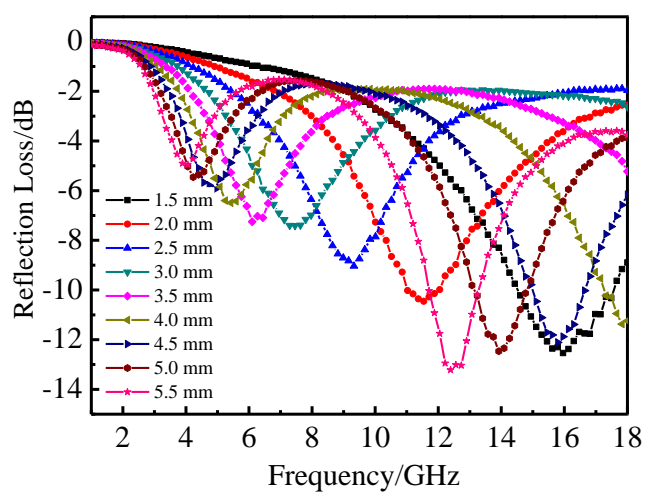

Fig.7 Frequency dependence of the reflection loss (RL) for the cobalt particles/paraffin composite specimens with various thicknesses

impedance of free space, and $Z_{\text {in }}$ is the input impedance of the absorber. According to Eqs.(2) and (3), the simulations of the RL of the cobalt particles composites with different thicknesses are shown in Fig.7. A maximum reflection loss of $-13.2 \mathrm{~dB}$ is achieved at $12.4 \mathrm{GHz}$ for the cobalt particles with a thickness of $5.5 \mathrm{~mm}$, and the effective absorption bandwidth $(\leq-10 \mathrm{~dB})$ is $1.6 \mathrm{GHz}$. According to the results shown above, cobalt particles have strong absorption of microwaves, which may be due to the specific microstructure of cobalt particles.

\section{Conclusions}

1) The quasi spherical cobalt particles, with a mixture of fcc and hcp-cobalt, are synthesized through a simple low-cost liquid reduction method.

2) A less saturation magnetization and a larger coercivity for the cobalt particles are achieved compared to the bulk cobalt. Dual-nonlinear dielectric resonances are obtained in the whole frequency range of $1 \sim 18 \mathrm{GHz}$.

3) The value of the minimum RL is $-13.2 \mathrm{~dB}$ at $12.4 \mathrm{GHz}$ for the cobalt particles with a thickness of $5.5 \mathrm{~mm}$, and the effective absorption bandwidth $(\leq-10 \mathrm{~dB})$ is $1.6 \mathrm{GHz}$.

\section{References}

1 Wang Z H, Han Z, Geng D Y et al. Chemical Physics Letters[J], 2010, 489(4-6): 187

2 Zhuo R F, Qiao L, Feng H T et al. Journal of Applied Physics[J], 2008, 104(9): 094101

3 Qiao L, Han X H, Gao B et al. Journal of Applied Physics[J], 2009, 105(5): 053911

4 Qiao L, Wen F, Wei J Q et al. Journal of Applied Physics[J], 2008, 103(6): 063903

5 Wu M Z, Zhang H J, Yao X et al. Journal of Physics D: Applied Physics[J], 2001, 34(6): 889

6 Pan S K, Lin P H, Wang L et al. Rare Metal Materials and Engineering [J], 2014, 43(4): 803 
7 Zhuo R F, Feng H T, Liang Q et al. Journal of Physics D: Applied Physics[J], 2008, 41(18): 185405

8 Sun Y P, Feng C, Liu X et al. Materials Research[J], 2014, 17(2): 477

9 Oyharçabal M, Olinga T, Foulc M P et al. Composites Science and Technology[J], 2013, 74: 107

10 Musal H M, Hahn H T, Bush G G. Journal of Applied Physics[J], 1988, 63(8): 3768

11 Liu Q Y, Guo X H, Chen J L et al. Nanotechnology[J], 2008, 19(36): 2618

12 Dutta P, Dunn B C, Eyring E M et al. Chemistry of Materials[J], 2005, 17(20): 5183

13 Puntes V F, Krishnan K M, Alivisatos P. Applied Physics Letters[J], 2001, 78(15): 2187

14 Zhu Y C, Zheng H G, Yang Q et al. Journal of Crystal Growth[J], 2004, 260(3-4): 427

15 Tong G X, Yuan J H, Wu W H et al. CrystEngComm[J], 2012, 14(6): 2071
16 An Z G, Zhang J J, Pan S L. Materials Chemistry and Physics[J], 2010, 123(2-3): 795

17 Li M, Xie K N, Wu Y Z et al. Materials Letters[J], 2013, 111: 185

18 Li T, Liu Y, He D L et al. Rare Metal Materials and Engineering $[\mathrm{J}], 2012$, 41(9): 1527

19 Zhang Y J, Yao Q, Zhang Y et al. Crystal Growth \& Design[J], 2008, 8(9): 3206

20 Li X G, Murai T, Saito T et al. Journal of Magnetism and Magnetic Materials[J], 1998, 190(3): 277

21 Zhou W, Zheng K, He L et al. Nano Letters[J], 2008, 8(4): 1147

22 Tong G X, Wu W H, Qiao R et al. Journal of Materials Research[J], 2011, 26(13): 1639

23 Wang X H, Zhu Z Y, Manchon A et al. Applied Physics Letters [J], 2013, 102(11): 111604

24 Matsumoto M, Miyata Y. IEEE Transactions on Magnetics[J], 1997, 33(6): 4459

\title{
球形钴颗粒的制备及吸波性能研究
}

\author{
孙万硕, 李 红, 刘 颖, 赵修臣, 程荆卫, 温术来 \\ (北京理工大学, 北京 100081)
}

\begin{abstract}
摘 要: 以 $\mathrm{CoSO}_{4} \cdot 7 \mathrm{H}_{2} \mathrm{O}$ 为钴源, $\mathrm{C}_{4} \mathrm{H}_{4} \mathrm{KNaO}_{6} \cdot 4 \mathrm{H}_{2} \mathrm{O}$ 为络合剂, $\mathrm{N}_{2} \mathrm{H}_{4} \cdot 4 \mathrm{H}_{2} \mathrm{O}$ 为还原剂, $\mathrm{NaOH}$ 为 $\mathrm{pH}$ 调节剂, CTAB为形貌控制剂, 通过液相 还原法成功制备出了具有特殊形貌的球形钴颗粒。采用扫描电子显微镜（SEM）, X-射线衍射仪（XRD）, 振动样品磁强计（VSM）以 及矢量网络分析仪对钴颗粒形貌、晶体结构、静磁性能以及微波频段内的电磁参数进行表征。研究表明钴颗粒的比饱和磁化强度为 123 $\left(\mathrm{A} \cdot \mathrm{m}^{2}\right) / \mathrm{kg}$, 矫顽力为 $176 \times 79.6 \mathrm{~A} \cdot \mathrm{m}^{-1}$ 。钴颗粒在 $9.8 、 15 \mathrm{GHz}$ 时出现明显介电损耗峰。钴颗粒复磁导率实部随着频率增加逐渐降低, 显示 了良好的频散特性，而虚部在微波频段内呈现宽化的共振峰，经分析为自然共振和交换共振共同作用所致。根据传输线原理计算反射损 耗, 发现当厚度为 $5.5 \mathrm{~mm}$ 时在 $12.4 \mathrm{GHz}$ 处得到最大反射损耗 $-13.2 \mathrm{~dB}$, 此时有效损耗频宽（ $\leq-10 \mathrm{~dB} ）$ 为 $1.6 \mathrm{GHz}$, 表明实验制备的钴颗 粒具有良好的吸波特性。
\end{abstract}

关键词：球形钴颗粒；液相还原法；静磁性能；电磁参数；吸波性能

作者简介: 孙万硕, 男, 1989 年生, 硕士生, 北京理工大学材料学院, 北京 100081, E-mail: sunwanshuo@ 163.com 